\title{
International Medical Society of Paraplegia Annual Scientific Meeting, Perth, Western Australia, 10 May 1988. Official Opening Address by His Excellency Professor Gordon Reid A.C., Governor of Western Australia
}

Distinguished Guests, Ladies and Gentlemen

I am delighted to join you today for the 27th Annual Meeting of the International Medical Society of Paraplegia.

This year your Society is meeting in the Southern hemisphere. I find this fact a very welcome acknowledgement of this nation's bicentenary celebrations-and also, of the contribution which Australian medical specialists have made to the study and treatment of paraplegia, both within Australia and as part of the international medical fraternity generally.

In 1988, our bicentennial year, Australians are focusing their attention on the legacy of achievement which has been left to us by the men and women-both black and white-who helped to build our nation. In so doing, our forbears were often compelled to overcome a formidable series of obstacles, environmental, material and emotional. The tenacity and the degree of resolution of these early Australians is a tribute to them and a message to us. It reminds us not only of what can be accomplished, but also of the kinds of determination which is required amidst adversity.

Similarly, my limited reading in the field of paraplegia has impressed upon me the considerable advances which have been achieved in its study and treatment within this century, and especially within the last 50 years, again, the advances have not been achieved easily.

Your Society's journal, Paraplegia, recorded in its silver jubilee issue (volume 25,1987 ) that members of the medical profession have been making observations about the workings of the spinal cord since the time of the ancient Persians, Greeks and Romans. Professor J. T. Hughes of the Radcliffe Infirmary, Oxford, quoted from The Edwin Smith Surgical Papyrus (now in New York), said to be 4000 years old. He attributes the authorship to the great architect and physician Imotep. Imotep diagnosed paraplegia as a human condition:

One having a dislocation in a vertebra of his neck, while he is unconscious of his two legs and his two arms, and his urine dribbles. An ailment not to be treated!

The Edwin Smith Papyrus is an amazing record of 48 cases of bodily injury, with the author's case reports. The last case, No. 48, is the most interesting, dealing with the spine. In the middle of this case, the scribe breaks off-presumably because of some urgent pressing business, and leaves the modern reader suspended, and also astounded, that such powers of perception and clarity of expression were exercised in those early days (Hughes, 1988). 
It was not until the First World War (1914-1918), with its large number of spinal injury cases, that this central field of study, central to an understanding of the human body, began to achieve any real prominence as a speciality in itself, as an area of hope rather than one of frustration and despair. Neglected by most communities until the mid-1940s, paraplegia looks to me to be the greatest handicap that man can sustain. As a disability it is harsh and persistent.

The name of Sir Ludwig Guttmann will, I expect, be known to all of you. It is synonymous with those developments in this field since the 1940s. Sir Ludwig was the highly distinguished founder of the International Medical Society of Paraplegia in 1961 and of the society's Journal, Paraplegia, in 1963. He pioneered the concept of sport for the disabled and was instrumental in establishing the Stoke Mandeville Games in 1948.

Whilst the first two of Guttmann's creations must figure as important landmarks from a medical point of view, it has I think been the increasing involvement of disabled people in both disabled and non-disabled competitive sports which has proved a most significant development from a humanitarian viewpoint.

Sir George Bedbrook has noted in his book, Lifetime care of the Paraplegic patient (1985) that:

As (a) regular activity for the paraplegic and tetraplegic, sport has many advantages-it improves the standard of living, (it) raises self-esteem, (it) improves the fitness of the particular person, (it) increases their education, improves neuromuscular coordination, instils a sense of self-discipline and instils the importance of daily training ...

\section{Whilst;}

the tremendous interest engendered in travelling with teams to competitive areas, perhaps only at club level, gives the disabled person a much greater horizon and a much keener interest in the community as a whole (pp 213,215)

From the general public's perspective, the image of a passive, despondent paraplegic is rapidly being replaced by one of active, healthy, individuals interested in life and in reassuming a normal role within the community.

That this has been possible is largely due to the efforts of members of the medical profession such as yourselves, who have not only made considerable innovations in the study of spinal cord paralysis, but also in the whole approach to the treatment and rehabilitation of paraplegics and tetraplegics.

As late as 1934 , the mortality rate of American paraplegics was over $80 \%$ (Bedbrook, 1987).

Historically, many of those with spinal cord paralysis have sustained their injuries on the battlefield, figiting for their country. Unhappily, the dedication of these soldiers was often met with relegation to a hospital or nursing home, there to live out whatever time might remain to them. In 1988, encouraged by the example of many competent enthusiasts, and by medical advances, the community's image of paraplegics and of the disabled is now vastly different.

Today, many paraplegics are able to benefit from the comprehensive treatment model which was advocated so strongly by Guttmann. Patients with spinal cord injuries are now admitted to hospital with due speed; in Western Australia, often via the flying doctor service. Once-admitted, they may join a spinal injuries unit, such as the one at the Royal Perth Rehabilitation Hospital in Shenton Park, the first such unit in Australia. There, they are treated by a paramedical 
team well equipped to deal with the specialised nature of their disorder. The patient is also introduced to a variety of therapies, ranging from art to sport. These avenues may be pursued during later attendance at outpatient review clinics, or at paraplegic-quadraplegic centres designed to assist them in readjusting to normal life.

This new, positive, outlook which the International Medical Society of Paraplegia has helped to win for those with spinal disabilities, is reflected in the medical profession's growing emphasis upon lifetime care for the paraplegic patient. This is a far cry from the largely pessimistic outlook which prevailed at the turn of the century.

Indeed, in 1969 (less than 20 years ago), Professor W. F. Windle, in addressing the Spinal Cord Injury Conference at the New York University Medical School, stated:

There is little interest at the present time in spinal cord regeneration. The one word most commonly associated with this term is impossible. (Remember the Smith Papyrus: 'An ailment not to be treated').

In recent years, however, such long held beliefs have begun to be questioned and a number of institutions have taken up the challenge. It is encouraging to learn of the upsurge of interest that is presently occurring in basic research work in this field.

This is to say that paraplegia, one of mankind's most harsh personal tragedies, has been responded to in a humane, personal way by a number of remarkable people who have sought to bring their professional expertise, and their compassion, to bear upon the problem.

Yet paraplegia is also a community tragedy, one which belongs to each of us in the sense that all of us living in a community are our brother's or our sister's keeper.

Horace, the Roman poet ( 65 to $8 \mathrm{BC}$ ) once said: 'What does it avail you, from many thorns, to pluck out one.'

Spinal injuries are complex, physically as well as mentally and socially. It behoves us to take the wider view, not pluck at only one aspect at a time.

In his welcoming address to a technical meeting on the topic 'Towards Prevention of Spinal Cord Injury' held in Perth in November 1987, the Hon Minister for Health, Mr Taylor, noted:

It is an unhappy fact of life that spinal cord injury in Australia mainly affects our young people. More than $50^{\circ}$ o of those with these injuries are under 25 years of age.

Spinal cord injury is a malady which affects most the young adult male; $82 \%$ are males and $70 \%$ are aged between $21-39$ years. (Burke and Toscano, 1987).

In addition, $\mathrm{Mr}$ Taylor said:

It has been estimated that at present there are more than 6000 people with spinal cord injuries in Australia. The number is increasing at the rate of 380 a year.

Clearly, there is an urgent need to reduce this incidence of spinal cord injury. With cure to this harsh, debilitating affliction still decades away, and even then costly, prevention is economically, socially and for human compassionate reasons, far less costly than any other treatment.

The World Health Organization believes that $50 \%$ of all disability is pre- 
ventable. Hence, we should make it our goal to reduce by half the yearly incidence of spinal injuries in Australia. This is a worthwhile and, I believe, attainable goal, if we all work together to achieve it.

Each of us in the community has a part to play towards achieving this goal, the medical profession, police, motor vehicle engineers, road engineers, safety authorities, employers, employees, sports administrators, teachers and parents.

Recent initiatives being undertaken by organisations and authorities to reduce the incidence of spinal injuries have focused on community education (advertising media, speakers, educators) the desired aim being to motivate people to take a real interest in their own safety and health. I am confident that such community education-by increasing public awareness of the profound effects of spinal cord injury, improving public knowledge of its major causes, and developing positive safety attitudes-will result in a reduced incidence of paraplegic and tetraplegic casualties.

The community education I have spoken of can go a long way to further improving the public's awareness of the special needs of the spinal injured living in our community.

The past 3-4 decades have shown us all that the personal tragedy of paraplegia need not be an insurmountable one.

By harnessing human compassion, human expertise and human resilience, we can create a formidable combination of human qualities, a combination which is increasingly well equipped to deal with the varied difficulties which, unfortunately, members of our respective communities experience, usually unexpectedly. Your conference is directed towards facilitating the provision of relief for many human beings afflicted in this way.

When action to overcome people's ailments provides immediate profit for those who respond, for example, for suppliers and manufacturers, it is usually an easy matter to bring the two parties, the afflicted and the creators of remedial devices, together. This is how seat belts and crash helmets for cyclists became popular.

But where remedies do not provide such a direct benefit, but require broader social initiatives, for example, improved road engineering, controlled speed limits, preventative drug education, anti-drink driving etc., the task is more difficult. Here public awareness is the vital ingredient. Here, we need to count the community assets we have in our midst. I see our community's assets in these respects in two major categories:

First the potential of the young people in our midst and in the educational system. Their fertile minds are receptive to messages about 'drug awareness' and the longer term effects of drugs upon our society; they are receptive about paraplegia and the effects of poorly designed roads, of the dangers of unnecessarily powerful motor vehicles and motorcycles, and of sporting practices with a high potential for spinal injury. I cannot believe that young people would ignore messages in this vein. The point is to try to get the message across to them.

Secondly, the value of the Australian federal system of government; the potential of the 'contagion effect' of social change whereby advances and advantages gained in one state are readily copied in another; and where the failures of one state are rejected by the others. We should exploit that asset; it calls for a selective, diverse approach to the problem.

There is much to be done. I warmly congratulate the International Medical 
Society of Paraplegia on its past achievements, and wish each of you every success in your present, very worthy endeavours.

So it is now with sincere pleasure that I declare the 27th Annual Meeting of the International Medical Society of Paraplegia for 1988 to be officially open.

The Editor is most grateful to his excellency Professor Gordon Reid A.C. for his permission to publish his inspiring and extremely thoughtful opening address in Paraplegia.

\section{References}

BEDBROOK G 1987 The development and care of spinal cord paralysis. Paraplegia 25: 178. Burke, Toscano 1987 Menzies Foundation Technical Report, New York.

HuGHES JT 1988 The Edwina Smith surgical papyrus: An analysis of the first case reports of spinal cord injuries. Paraplegia 26: 71-82. 